\title{
Lateralized periodic discharges associated with status epilepticus in the first year after stroke
}

\author{
Hava Ozlem Dede, Nerses Bebek, Ozlem Gelisin, Murat Mert Atmaca, Nilufer Yesilot Barlas, \\ Candan Gurses, Betul Baykan, Aysen Gokyigit
}

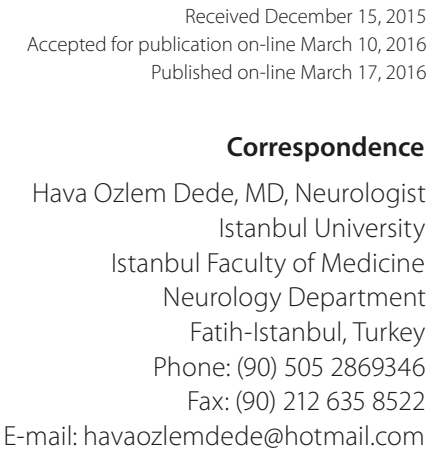

Received December 15, 2015 Accepted for publication on-line March 10, 2016 Published on-line March 17, 2016

Correspondence

Hava Ozlem Dede, MD, Neurologist Istanbul University Istanbul Faculty of Medicine Neurology Department Fatih-Istanbul, Turkey Phone: (90) 5052869346 Fax: (90) 2126358522 E-mail: havaozlemdede@hotmail.com

\section{SUMMARY}

Backgrand. Lateralized periodic discharges (LPDs) are infrequent electroencephalograph (EEG) findings, and may present in ictal or interictal form. They are regarded as potential electrophysiologic signs of convulsive or nonconvulsive status epilepticus (NCSE). We report four patients who presented with NCSE and one who presented with convulsive status epilepticus in the postictal period, characterized by LPDs in EEG recordings in the first year after stroke.

Material and methods. We prospectively evaluated patients who clinically presented with status epilepticus associated LPDs between March 2014 and March 2015. We investigated patients that presented with a new stroke occurrence. We excluded the other LPD etiologies.

EEG studies of five patients (two men) who were admitted to our emergency unit with confusion, three of whom had visual symptoms; four were treated for NCSE as diagnosed with LPDs. The fifth patient had convulsive status epilepticus with LPD in the postictal period.

Results and Discussion. None of the five patients, who were aged between 68 and 92 years, showed any etiologic factor other than a history of cerebrovascular disease (CVD). Magnetic resonance imaging studies of the patients revealed old infarcts and transitional diffusion restrictions. The clinical and EEG findings decreased substantially upon antiepileptic drug treatment. Herein, we illustrate the first patient who had confusion, visual hallucinations, and ictal and interictal LPD in her consecutive EEGs.

Conclusions. CVDs may pave the way for LPDs in patients with a history of stroke because CVDs cause structural brain damage. Patients who present with a similar clinical profile and imaging signs of stroke should be checked for NCSE, particularly in the presence of LPDs in EEGs.

Key words: nonconvulsive status epilepticus - lateralized periodic discharges - focal seizures - MRI • negative symptoms

\section{BACKGROUND}

Periodic lateralized epileptiform discharges (PLEDs) were described in the 1960s as "usually observed with $1-2$ sec intervals in the form of periodical or semi-periodical spikes or sharp waves" (Chatrian et al., 1964). The American Clinical Neurophysiology Society's
(ACNS) subcommittee has suggested using "lateralized periodic discharges" (LPDs) instead of PLEDs (Hirsch et al., 2005). They are generally associated with acute structural lesions such as stroke, central nervous system (CNS) infections, fast-growing brain tumors, as 
well as presenting with acute metabolic disorder in patients with chronic structural damage (Janati et al., 1986). Most patients with LPDs demonstrate clinical seizures, whereas LPDs are often regarded as an interictal finding (Fitzpatrick and Lowry, 2007; Beniczky et al., 2013; Trinka and Leitnger, 2015).

Due to the fact that nonconvulsive status epilepticus (NCSE) may not show any clinical symptoms other than a confused state, it may be difficult to reach a diagnosis when it presents with negative symptoms like aphasia or blindness (Jirsch and Hirsch, 2007; Caboclo et al., 2016). In addition, brain magnetic resonance imaging (MRI) signs, similar to those observed during acute stroke, can be confused with findings that occur in status epilepticus due to cytotoxic and vasogenic edema, which further complicate the diagnostic process (Rennebaum et al., 2015). The presence of such findings obtained through brain imaging modalities in addition to a subtle clinical profile of NCSE with a background of cerebral vascular disease (CVD) may be confusing with regard to the differential diagnosis of acute stroke and status epilepticus.

\section{AIM}

In this study, we aimed to present four patients with NCSE who presented to our emergency unit with signs and symptoms of disorientation, visual hallucinations or sudden loss of vision and Wernicke-type aphasia, and a fifth patient who presented in the postictal period with confusion, after convulsive status epilepticus, having ictal/interictal focal seizure activity associated with LPDs in their EEG. We illustrate the first patient who had confusion, visual hallucinations, and ictal and interictal LPD in her consecutive EEGs. The other four patients are presented in Table 1.

\section{MATERIALS AND METHODS}

We prospectively evaluated five older patients between March 2014 and March 2015, who presented to the clinic with status epilepticus-associated LPDs. We studied patients who presented as though they were having a new attack of stroke. We excluded the other LPDs etiologies.

We evaluated EEG on the first day of admission, and repeated the evaluation the following day. We repeated EEG 4 times in the index case: at admission, the following day, after 2 weeks of admission because of clinical degradation, and then after clinical improvement in the third week.

Initial MRIs were performed in the first 1-4 hours of admission and repeated during the following days after clinical improvement.

\section{RESULTS}

We performed 436 emergency EEG exams between March 2014 and March 2015, and reported LPDs in only 6 patients. The excluded patient had viral epileptic encephalopathy. All of the remaining five patients, who were aged between 68 and 92 years, had LPDs in their EEGs and a previous history of stroke (at least 4 months before). MRI studies of the patients revealed old infarcts and transitional diffusion restriction in the first and second patients. The MRI findings were ipsilateral to clinical and EEG findings. The clinical and EEG findings decreased substantially with antiepileptic drug treatment.

Herein, we illustrated the index patient who had confusion, visual hallucinations, and ictal and interictal LPDs in her consecutive EEGs (see below).

Four patients presented with visual hallucinations, sudden loss of vision, Wernicke-type aphasia, and a confused state. They were classified as NCSE in accordance with the modified Salzburg consensus criteria for NCSE. The last patient presented with postictal status epilepticus and refractory LPD activity in the EEG. Two patients had hyperintense lesions in the acute phase as revealed under diffusion-weighted imaging (DWI). All five patients had LPD activity in their EEG. Clinical seizure semiology, LPD, and MRI findings were consistent.

The second patient had LPD activity in the previous seizure location along with both negative and positive clinical findings, which affirmed the location, such as seizure-related aphasia and loss of vision and hallucinations. However, the previous stroke was in the left MCA region, and the new imaging studies indicated the right temporo-occipital region. Three patients exhibited seizures in the occipital lobe, and two patients (N2 and N3) showed temporal lobe involvement, in addition to the clinical profile of aphasia. The new imaging findings independently suggested the involvement of the temporo-occipital region in the contralateral hemisphere in one patient (N2). On the other hand, the other patients (N3, N4 and N5) displayed no new sign in the imaging studies.

We administered diazepam $10 \mathrm{mg}$ iv, during EEG exam in 3 patients. We observed suppression of epileptiform discharges in all 3 patients' investigations. We then evaluated the clinical state and reported clinical 
improvement. Antiepileptic drugs were administrated to all 5 patients.

\section{The index case (N1)}

A right-handed woman aged 73 years was admitted to our emergency unit because of seizures. According to her relatives, she had turned her head and experienced sudden contractions in her left arm and leg, followed by loss of consciousness accompanied by foaming at the mouth. After this seizure, which lasted about 30 seconds, she had a tendency to sleep and presented to our emergency unit in a confused state. Her history revealed an infarction of the right middle cerebral artery (MCA) in the previous year. Three months after the stroke, she was prscribed levetiracetam $1000 \mathrm{mg} /$ day because of having seizures that caused contractions in her left arm and leg, which reportedly did not repeat during the past months.

Her neurologic examination showed a sleep tendency and she opened her eyes on demand; however, she had disorientation of time, place, and person, and also showed dysarthria. She had left hemiparesis that included her face. Her left plantar reflex was extensor. She had clouding of consciousness and appeared to talk with non-existing people, sometimes in an incoherent fashion, which was thought to be associated with complex visual hallucinations.

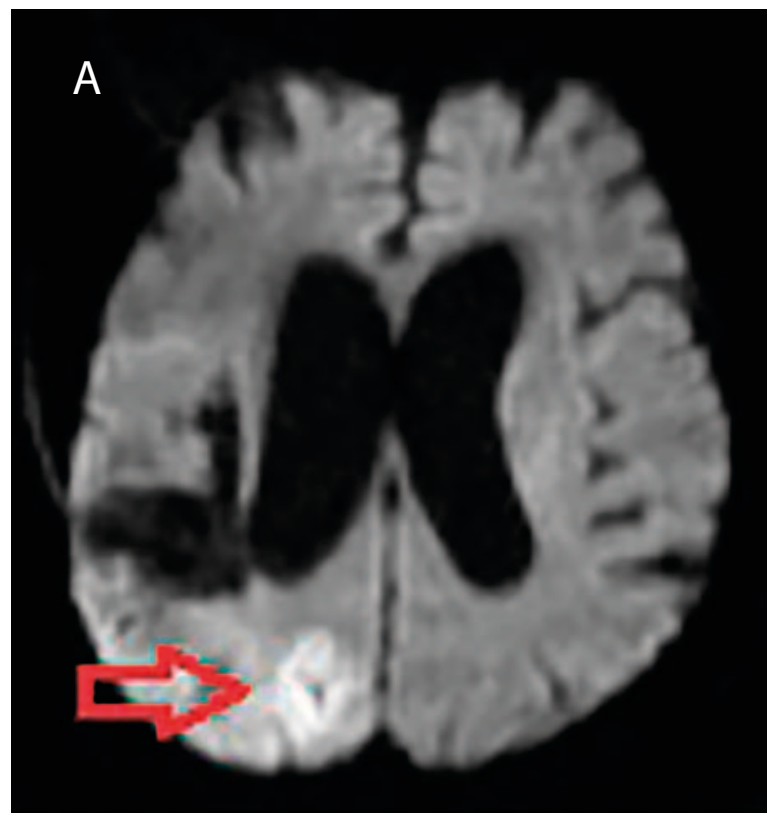

A diffusion-weighted cranial MRI (DWI) study performed on the day of admission showed hyper-intensity over the right occipital region and restriction in the apparent diffusion coefficient (ADC) map (Figure 1).

The EEG examination performed on the following day demonstrated high-amplitude continuous periodic sharp wave discharges that recurred at $1-1.5$ second intervals over the right hemisphere, in the occipital region. Fast rhythms of 14-16 Hz were observed (Figure 2). These periodic sharp wave discharges disappeared almost completely after the administration of $10 \mathrm{mg}$ IV diazepam (Figure 3). The patient displayed better communication, started to recognize her relatives, and began to talk after dozing off a little.

The levetiracetam dose was increased to $2000 \mathrm{mg}$ / day. The clinical follow-up of the patient revealed improvement in the confused state and she started to recognize her relatives. However, the 10-20-sec visual hallucinations persisted with fluctuating confusion.

The clinical follow-up showed a focal seizure activity in the form of rhythmic jerking in the index finger of the left hand and the left foot. Despite the administration of $10 \mathrm{mg}$ IV diazepam, the symptoms persisted for about 1 hour and were diagnosed as epilepsia partialis continua (EPC). Topiramate was added to the treatment regimen and the dosage was gradually elevated to $200 \mathrm{mg} /$ day. Two days after the EPC attack, she began

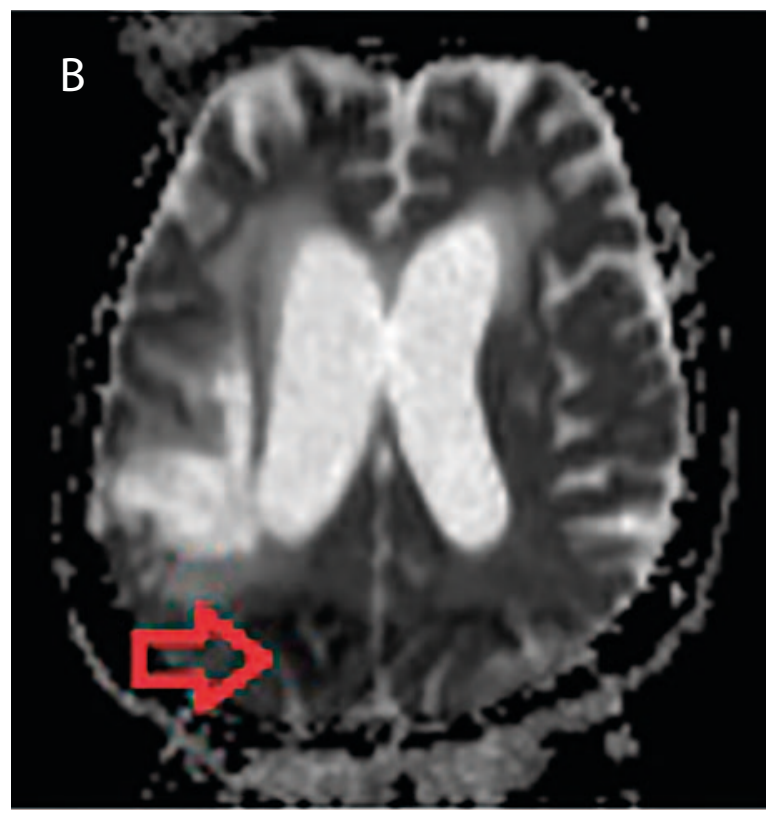

Figure 1. Diffusion-weighted cranial magnetic resonance images on the day of admission (March 31st, 2014) showing hyper-intensity (A) and the apparent diffusion coefficient diffusion restriction in the right occipital region (B). 


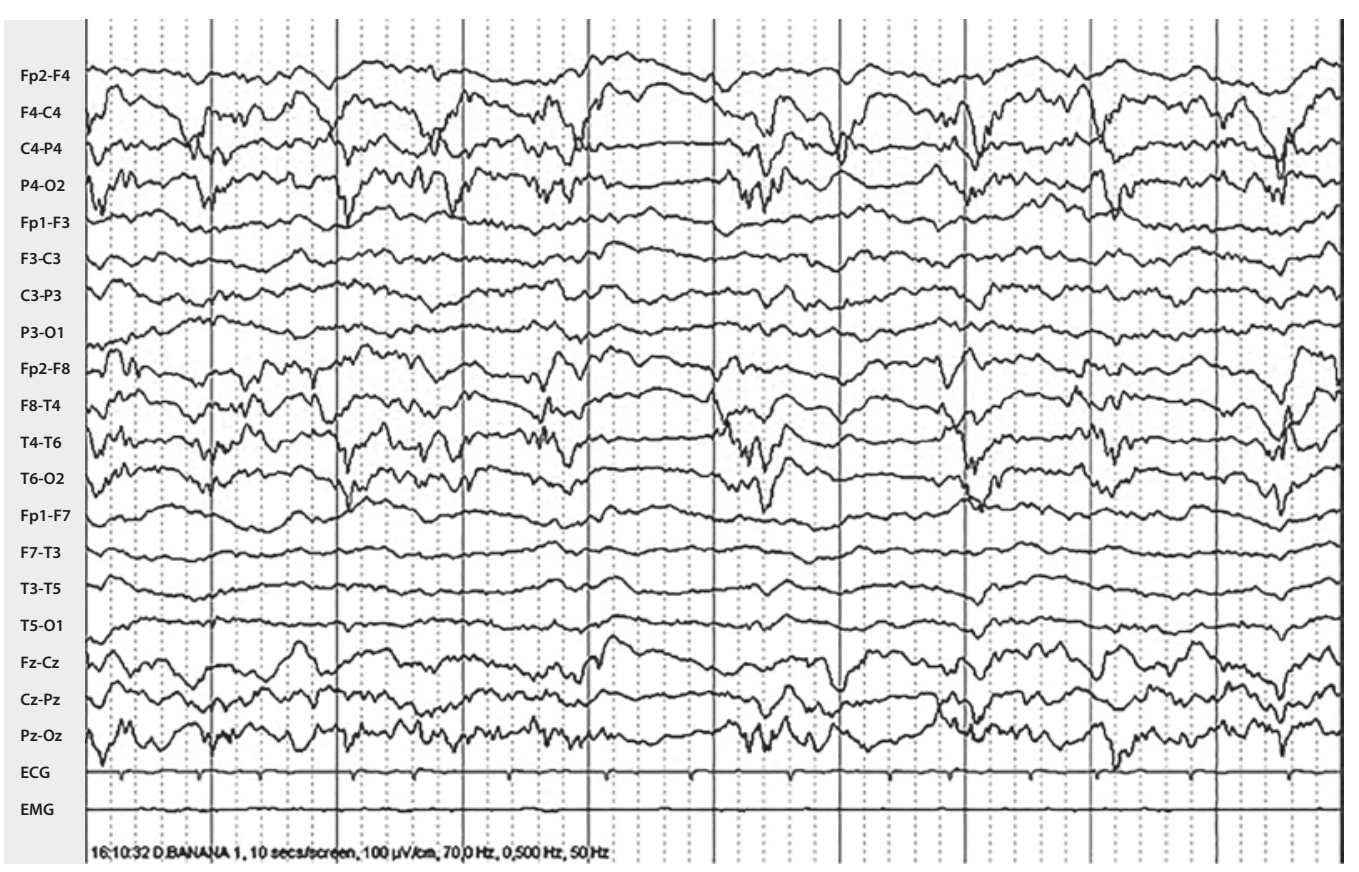

Figure 2. The EEG examination was performed on the second day of admission (April 1st, 2014). Fast rhythms of $14-16 \mathrm{~Hz}$ in addition to the periodic sharp waves of high amplitude that repeated every $1-1.5$ seconds in the occipital region of the right hemisphere. Clinically, the patient appeared to be in a confused state, babbled meaningless words, and failed to communicate.

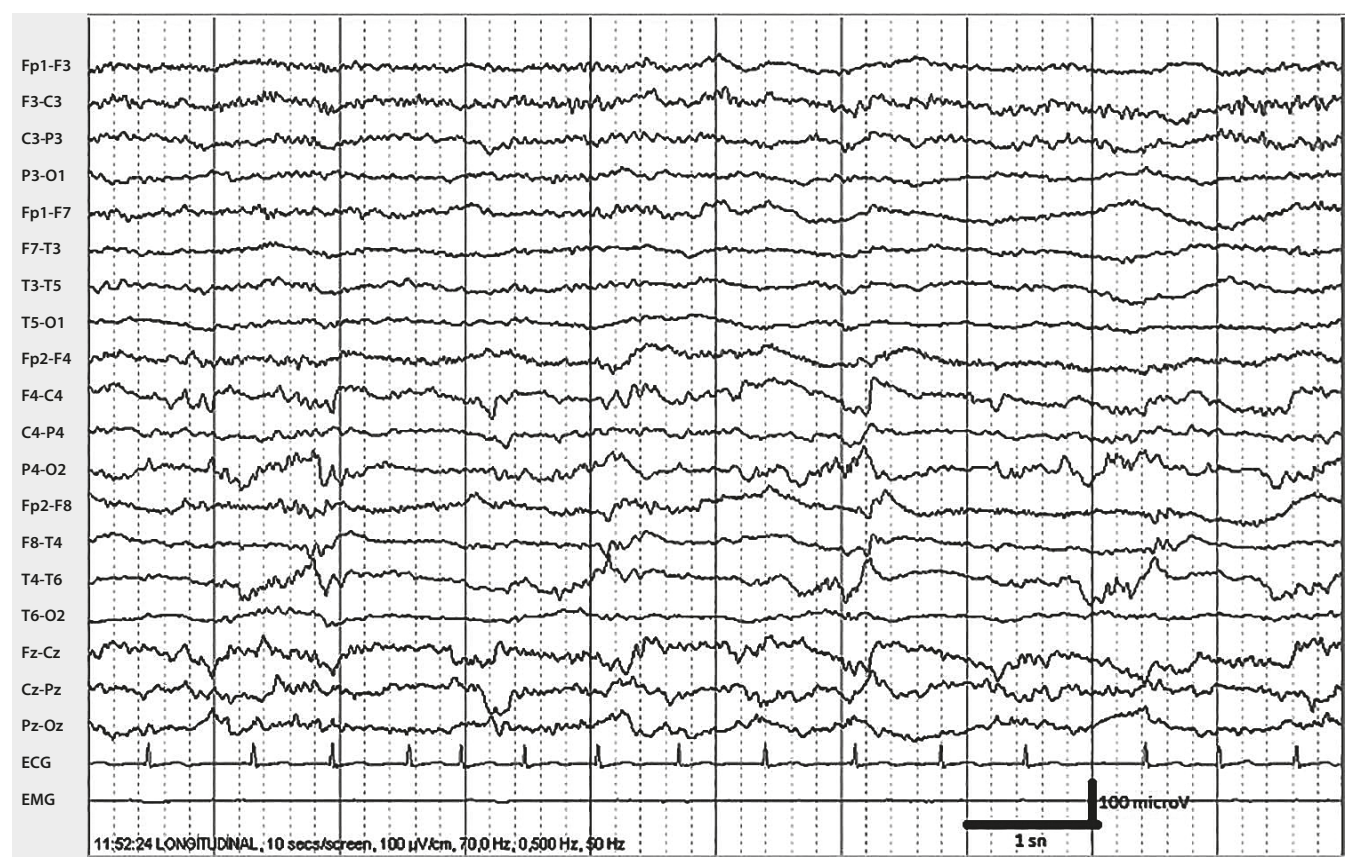

Figure 3. Following the administration of $10 \mathrm{mg}$ IV diazepam, previous EEG discharges (Figure 1) were almost suppressed, periodic sharp waves of low amplitude that repeated every 2-2.5 seconds in the occipital region of the right hemisphere. The patient displayed better communication, started to recognize her relatives, and began to talk. 


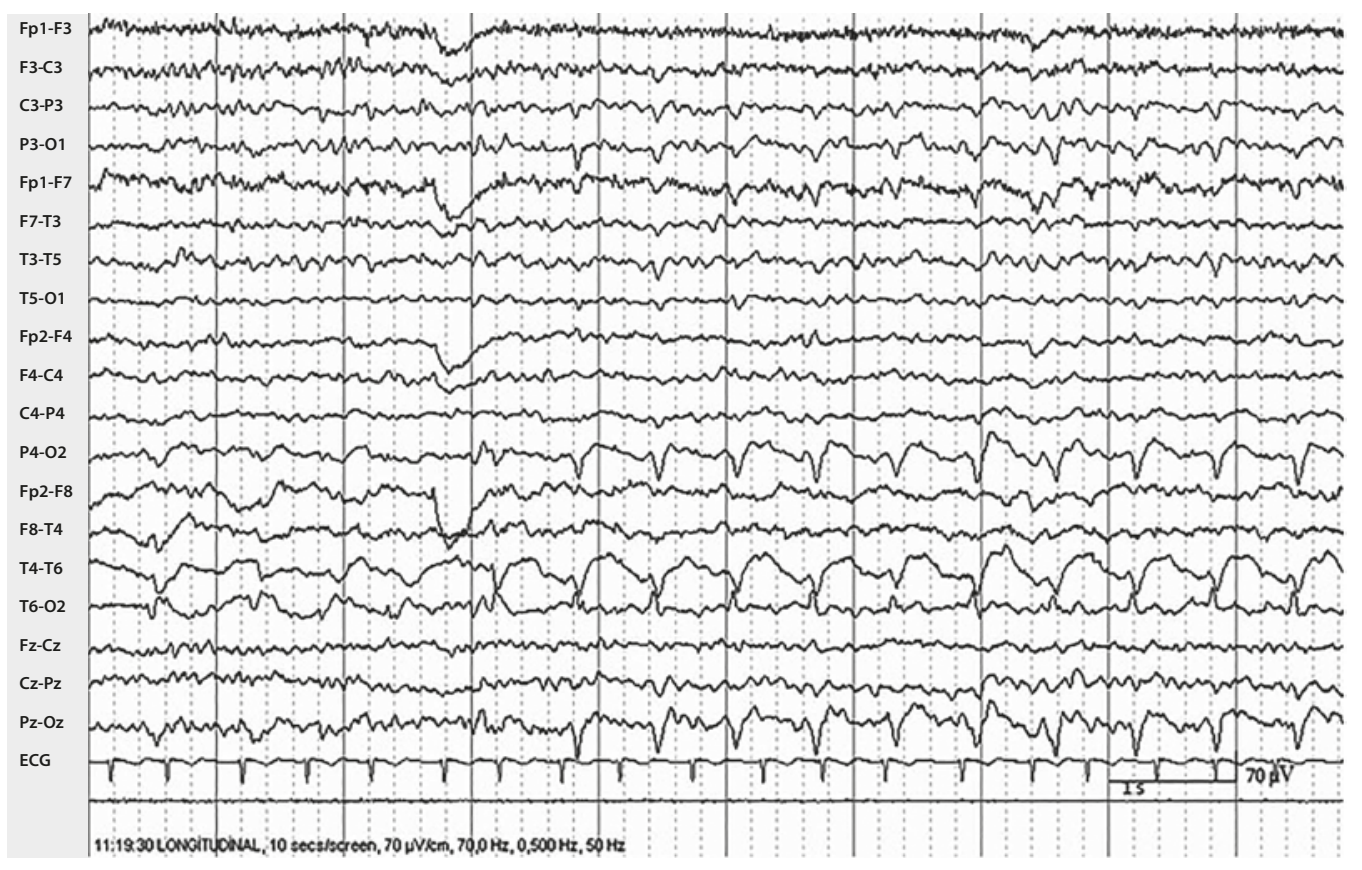

Figure 4. EEG examination in the second week: rhythmic sharp wave activity in the right temporooccipital region. During this time, the communication with the patient became poor again and her responses were meaningless.

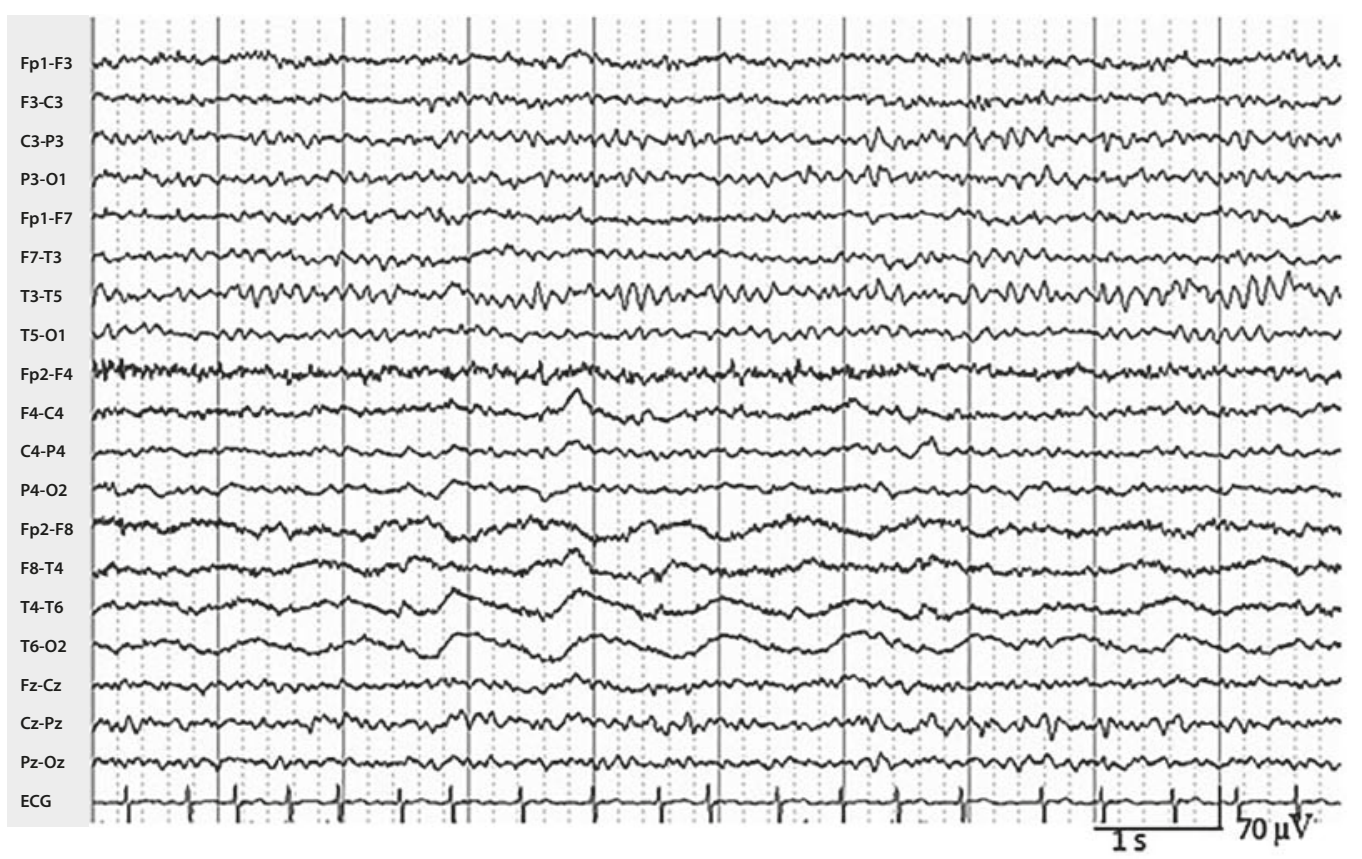

Figure 5. Following the administration of $10 \mathrm{mg}$ IV diazepam, the seizure activity resolved. After the diazepam infusion her cognition and communication was better. 

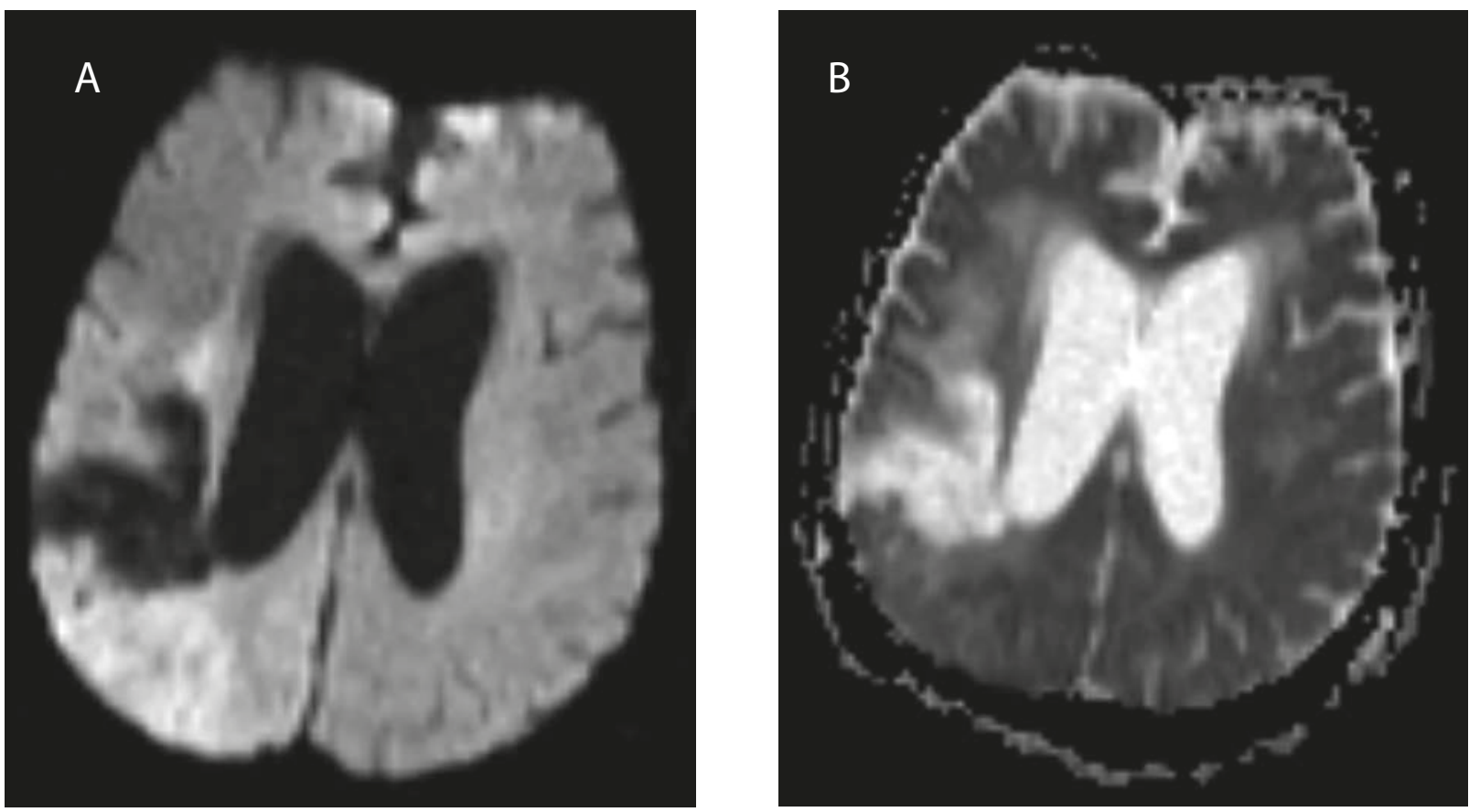

Figure 6. Diffusion-weighted cranial follow-up MRI 18 days after presentation (April 17, 2014) showing resolution of the hyper-intensity $(\mathbf{A})$ and the apparent diffusion coefficient diffusion restriction in the right occipital region (B).

to talk with non-existing people and had drowsiness. The repeat EEG exhibited sharp waves with low-moderate amplitude that were of continuous character and repeated rhythmically every second, with very brief intervals. These discharges were observed to spread over the right hemisphere from time to time (Figure 4). These discharges disappeared 37 seconds after the administration of $10 \mathrm{mg}$ iv diazepam (Figure 5), and her cognition and communication recovered better than before.

After the seizures were treated, her cranial MRI revealed resolution of the hyper-intensity in the DWI (Figure 6). We believe that the hyper-intensity was related to epileptiform activity; there was no lasting structural damage.

Afterwards, her clinical treatment took 3 weeks; the hallucinations disappeared and the disorientation to person, place and time was observed to be better with levetiracetam $2000 \mathrm{mg} /$ day and topiramate $200 \mathrm{mg} /$ day.

\section{DISCUSSION}

PLED/LPD activity is reported in $0.1-1 \%$ of routine EEG recordings (Fitzpatrick and Lowry, 2007) and categorized in two groups: complete PLED and PLED-plus. Complete PLED defines relatively stable, simple, and uniform discharges. PLED-plus is more closely related to seizure activity and consists of discharges accompa- nied by activities of low amplitude and rapid rhythms (Reiher et al., 1991). While evaluating the clinical significance of PLEDs, their characteristics such as frequency, stereotypy, background activity, and evolution/dynamics are also considered to be important determinants (Finnigan and van Putten, 2013; Trinka and Leitinger, 2015). PLED activity in 24-hour EEG recordings is reported to vary between PLED and PLED-plus, which is more closely correlated with seizure activity (Chong and Hirsch, 2005; Trinka and Leitinger, 2015). The presence of high frequency, rapid background activity, and chaotic stereotype, as in our first patient, was consistent with PLED-plus. In this patient, PLED/LPD was regarded as an ictal pattern (Figure 2) and focal seizure activity was also observed in the same region after the suppression of LPD. The EEG recordings of our other 4 patients demonstrated simultaneous presence of focal seizure activity and LPD in the same region. We could not demonstrate seizure activity with EEG in the last patient who had refractory LPD activity.

Almost $80 \%$ of patients with LPD exhibited focal seizure symptoms or focal neurologic signs (Andraus et al., 2012). In emergency units, patients who presented with LPD developed clinical seizures (90\%), generalized seizures (82.1\%), focal seizures (17.8\%), epilepsia partialis continua (10.7\%), or generalized status ep- 
Table 1. Clinical, electrophysiologic, and imaging characteristics of the patients

\begin{tabular}{|c|c|c|c|c|c|}
\hline & Patient 1 & Patient 2 & Patient 3 & Patient 4 & Patient 5 \\
\hline Age (year/sex) & $73 / F$ & $70 / \mathrm{M}$ & $68 / M$ & $92 / \mathrm{F}$ & $77 / F$ \\
\hline Neurologic signs & $\begin{array}{l}\text { Visual hallucination, } \\
\text { confusion, sequels of left } \\
\text { hemiplegia and dysarthria }\end{array}$ & $\begin{array}{l}\text { Loss of vision, } \\
\text { Wernicke aphasia, } \\
\text { confusion }\end{array}$ & $\begin{array}{l}\text { Visual hallucination, } \\
\text { Wernicke aphasia, } \\
\text { confusion }\end{array}$ & Confusion & $\begin{array}{l}\text { Spasticity on right } \\
\text { arm and leg }\end{array}$ \\
\hline $\begin{array}{l}\text { Time and location of } \\
\text { previous stroke }\end{array}$ & Previous year/ Right MCA & $\begin{array}{l}4 \text { months ago/Left } \\
\text { MCA }\end{array}$ & $\begin{array}{l}4 \text { months ago/Left } \\
\text { MCA }\end{array}$ & $\begin{array}{l}\text { A year ago/Left } \\
\text { MCA }\end{array}$ & $\begin{array}{l}5 \text { months ago/Left } \\
\text { MCA }\end{array}$ \\
\hline $\begin{array}{l}\text { Cranial MRI (Acute } \\
\text { period) }\end{array}$ & $\begin{array}{l}\text { DWI showing hyperintensity } \\
\text { in the right occipital region } \\
\text { and restriction in the ADC } \\
\text { map }\end{array}$ & $\begin{array}{l}\text { DWI showing } \\
\text { hyperintensity in the } \\
\text { right parietal region } \\
\text { and restriction in the } \\
\text { ADC map }\end{array}$ & No acute sign & No acute sign & No acute sign \\
\hline LPD localization & Right occipital region & Left temporal region & $\begin{array}{l}\text { Left temporo- } \\
\text { occipital region }\end{array}$ & $\begin{array}{l}\text { Left temporo- } \\
\text { occipital region }\end{array}$ & $\begin{array}{l}\text { Left centro-parietal } \\
\text { region }\end{array}$ \\
\hline Ictal EEG sign & $\begin{array}{l}\text { Right LPD-plus and right } \\
\text { temporo-occipital rhythmic } \\
\text { sharp waves }\end{array}$ & $\begin{array}{l}\text { Left occipito- } \\
\text { temporal sharp-slow } \\
\text { wave activity }\end{array}$ & $\begin{array}{l}\text { Left temporo- } \\
\text { parieto-occipital } \\
\text { rhythmic sharp-slow } \\
\text { waves }\end{array}$ & $\begin{array}{l}\text { Left temporo- } \\
\text { occipital region } \\
\text { LPD }\end{array}$ & Not applied \\
\hline $\begin{array}{l}\text { Clinical } \\
\text { improvement with } \\
\text { IV Diazepam } \\
\end{array}$ & + & Not applied & + & + & + \\
\hline Interictal EEG sign & $\begin{array}{l}\text { Right temporo-occipital } \\
\text { sharp and slow wave } \\
\text { paroxysms }\end{array}$ & Left temporal LPD & $\begin{array}{l}\text { Left temporo- } \\
\text { occipital LPD }\end{array}$ & $\begin{array}{l}\text { Generalized } \\
\text { slowing }\end{array}$ & $\begin{array}{l}\text { Left centro-parietal } \\
\text { LPD }\end{array}$ \\
\hline $\begin{array}{l}\text { Time period until } \\
\text { resolution of clinical } \\
\text { signs }\end{array}$ & 21 days & 5 days & 7 days & 7 days & 2 days \\
\hline Diagnosis & $\mathrm{NCSE}+\mathrm{EPC}$ & NCSE & NCSE & NCSE & SE \\
\hline $\begin{array}{l}\text { Antiepileptic } \\
\text { therapy }\end{array}$ & LEV + TPM & LEV & TPM & LEV & LEV \\
\hline
\end{tabular}

ADC - Apparent Diffusion Coefficient; BDZ - benzodiazepine; DWI - diffusion-weighted imaging; EPC - epilepsia partialis continua; M - Male; IV - intravenous; F - female; LEV - Levetiracetam; NCSE - nonconvulsive status epilepticus; SE - status epilepticus; MCA - middle cerebral artery; LPD - lateralized periodic discharge; TPM - Topiramate).

ilepticus (35.7\%) (Kate et al., 2012). Although LPDs are known to be observed during the ictal period and resistant against antiepileptic drug therapy (Brenner and Schaul, 1990), the authors pointed out that LPDs associated with confused state may benefit from antiepileptic drug treatment. In our cases, the focal seizure activity observed during the EEG recording resolved with IV benzodiazepine therapy; however, the concomitant LPD activity persisted in the acute period, albeit suppressed a little in terms of amplitude. After the application of the antiepileptic drug treatment, the LPD activity resolved in four of the patients. Although significant clinical improvements were observed in the first patient who was unresponsive to the treatment, followup EEGs showed that LPD activity resolved at 3 weeks but the epileptiform activity persisted. In the other three patients who received antiepileptic drug therapy,
LPD resolved within 5-7 days. The last patient presented with status epilepticus and the LPD activity was intractable despite clinical improvement.

EEG abnormalities can be observed in various forms after CVD. During the acute phase, seizures may present with ictal epileptic discharges, whereas focal or diffuse slow waves may accompany during the subacute/ chronic phases (Finnigan and van Putten, 2013). LPDs can be detected both during the acute and subacute phases (Fitzpatrick and Lowry, 2007). In our patients, there were no new lesions that could explain the etiology behind LPD. The clinical profile developed after almost a year following the previous seizure. LPDs were consistent with the lateralization of the stroke; however, the first patient had a different location. In patient $\mathrm{N} 1$, although there was a past right MCA infarction, the new seizure semiology, imaging findings, and the 
LPD location indicated the right occipital region. The resolution of the hyper-intensity and the ADC diffusion restriction in the right occipital region on the third week is believed to have been a seizure-induced edema area rather than a new lesion (Rennebaum et al., 2016).

In general, LPD activity in patients with chronic cerebral disease showed an acute state with increasing clinical seizure activity (Baykan et al., 2000). Patients with LPDs may demonstrate isolated focal or generalized seizures, whereas nonconvulsive status epilepticus or epilepsia partialis continua may also be observed (Schraeder and Singh, 1980). LPDs may develop due to various reasons as a result of increased neuronal excitability associated with the recently-experienced seizures (Baykan et al., 2000). Single-photon emission computerized tomography (SPECT) studies, that investigated the relationship of LPDs with ictal state, showed hyper-fusion during activity and hypofusion after the activity in the LPD areas, which suggested that LPDs are ictal phenomena (Assal et al., 2001). On the other hand, many studies including video EEG monitoring have revealed LPD activity as an interictal finding, independent from the ictal state (Terzano et al., 1986; Sierra-Marcos et al., 2015). Moreover, longterm follow-up studies indicated LPD activities being persistent for years (PeBenito and Cracco, 1979; Gurer et al., 2004). The fact that LPD activity is electrophysiologically suppressed by the administration of benzodiazepines during the acute period further supported the view that LPDs were an ictal discharge, at least on some occasions (Claassen, 2009). During the chronic period, the recommended treatment includes antiepileptic drugs such as carbamazepine, valproate, and felbamate (Hughes, 2010).

\section{CONCLUSION}

Patients who have fluctuating positive and negative clinical symptoms should be evaluated with EEG. NCSE may present like stroke episodes. LPDs could be interictal discharges and ictal signs.

\section{CONFLICT OF INTEREST DISCLOSURE}

The author has no conflict of interest to declare.

\section{REFERENCES}

Andraus M.E., Andraus C.F., Alves-Leon S.V.: Periodic EEG patterns: importance of their recognition and clinical significance. Arquivos de Neuro-Psiquiatria, 2012, 70: 145-151.

Assal F., Papazyan J.P., Slosman D.O., Jallon P., Goerres
G.W.: SPECT in periodic lateralized epileptiform discharges (PLEDs): a form of partial status epilepticus? Seizure, 2001, 10: 260-265.

Baykan B., Kinay D., Gokyigit A., Gurses C.: Periodic lateralized epileptiform discharges: association with seizures. Seizure, 2000, 9: 402-406.

Beniczky S., Hirsch L.J., Kaplan P.W., Pressler R., Bauer G., Aurlien H., Brogger J.C., Trinka E: Unified EEG terminology and criteria for nonconvulsive status epilepticus. Epilepsia, 2013, 54, Suppl. 6: 28-29.

Brenner R.P., Schaul N.: Periodic EEG patterns: classification, clinical correlation, and pathophysiology. J. Clin. Neurophysiol., 1990, 7: 249-267.

Caboclo L.O., Sanches P.R., da Costa Neves R.S., de Almeida Pimentel P.C.: De novo aphasic status epilepticus presenting with frontal periodic lateralized epileptiform discharges. Clinical Neurophysiology, 2016, 127: 973-975. doi: 10.1016/j. clinph.2015.05.001. Epub 2015 May 11.

Chatrian G.E., Shaw C.M., Leffman H.: The significance of periodic lateralized epileptiform discharges in EEG: An electrographic, clinical and pathological study. Electroencephalogr. Clin. Neurophysiol., 1964, 17: 177-193.

Chong D.J., Hirsch L.J.: Which EEG patterns warrant treatment in the critically ill? Reviewing the evidence for treatment of periodic epileptiform discharges and related patterns. J. Clinical Neurophysiol., 2005, 22: 79-91.

Claassen J.: How I treat patients with EEG patterns on the ictal-interictal continuum in the neuro ICU. Neurocritical Care, 2009, 11: 437-444.

Finnigan S., van Putten M.J.: EEG in ischaemic stroke: quantitative EEG can uniquely inform (sub-)acute prognoses and clinical management. Clin. Neurophysiology, 2013, 124: 10-19. Fitzpatrick W., Lowry N.: PLEDs: clinical correlates. Canad. J. Neurologic. Sc., 2007, 34: 443-450.

Gurer G., Yemisci M., Saygi S., Ciger A.: Structural lesions in periodic lateralized epileptiform discharges (PLEDs). Clinical EEG Neurosci., 2004, 35: 88-93.

Hirsch L.J., Brenner R.P., Drislane F.W., So E., Kaplan P.W., Jordan K.G., Herman S.T., LaRoche S.M., Young B., Bleck T.P., Scheuer M.L., Emerson R.G.: The ACNS subcommittee on research terminology for continuous EEG monitoring: proposed standardized terminology for rhythmic and periodic EEG patterns encountered in critically ill patients. J. Clinical Neurophysiol., 2005, 22: 128-135.

Hughes J.R.: Periodic lateralized epileptiform discharges: Do they represent an ictal pattern requiring treatment? Epilepsy Behav., 2010, 18: 162-165.

Janati A., Chesser M.Z., Husain M.M.: Periodic lateralized epileptiform discharges (PLEDs): a possible role for metabol- 
ic factors in pathogenesis. Clinical EEG (electroencephalography), 1986, 17: 36-43.

Jirsch J., Hirsch L.J.: Nonconvulsive seizures: developing a rational approach to the diagnosis and management in the critically ill population. Clin. Neurophysiol., 2007, 118: 1660-1670. Kate M.P., Dash G.K., Radhakrishnan A.: Long-term outcome and prognosis of patients with emergent periodic lateralized epileptiform discharges (ePLEDs). Seizure, 2012, 21: 450-456.

PeBenito R., Cracco J.B.: Periodic lateralized epileptiform discharges in infants and children. Annals Neurol., 1979, 6: 47-50. Reiher J., Rivest J., Grand'Maison F., Leduc C.P.: Periodic lateralized epileptiform discharges with transitional rhythmic discharges: association with seizures. Electroencephalography and Clinical Neurophysiology, 1991, 78: 12-17.

Rennebaum F., Kassubek J., Pinkhardt E., Hubers A., Ludolph
A.C., Schocke M., Fauser S.: Status epilepticus: Clinical characteristics and EEG patterns associated with and without MRI diffusion restriction in 69 patients. Epilepsy Res., 2015, 120: 55-64. Schraeder P.L., Singh N.: Seizure disorders following periodic lateralized epileptiform discharges. Epilepsia, 1980, 21: 647-653. Sierra-Marcos A., Scheuer M.L., Rossetti A.O.: Seizure detection with automated EEG analysis: a validation study focusing on periodic patterns. Clin. Neurophysiol., 2015, 126: 456-462. Terzano M.G., Parrino L., Mazzucchi A., Moretti G.: Confusional states with periodic lateralized epileptiform discharges (PLEDs): a peculiar epileptic syndrome in the elderly. Epilepsia, 1986, 27: 446-457.

Trinka E., Leitinger M.: Which EEG patterns in coma are nonconvulsive status epilepticus? Epilepsy \& Behavior, 2015, 49: 203-222. 